\title{
PENGETAHUAN GIZI DAN KESEHATAN, PERILAKU HIDUP SEHAT, SERTA KARAKTERISTIK LINGKUNGAN FISIK RUMAH HUBUNGANNYA DENGAN KELUHAN KESEHATAN SOPIR ANGKOT
}

(The Correlation Between Nutrition and Health Knowledge, Behavior of Healthy Life, and Physical Characteristic of The House Towards Health Sighs of Public Transportation Driver)

\author{
Arina Rizkiana ${ }^{1}$, Siti Madanijah ${ }^{2 *}$, dan Yekti Hartati Effendi ${ }^{2}$ \\ 1 Departemen Gizi Masyarakat dan Sumberdaya Keluarga, Fakultas Ekologi Manusia, Institut \\ Pertanian Bogor, Bogor 16680. \\ ${ }^{2 * *}$ Alamat korespondensi: Departemen Gizi Masyarakat, Fakultas Ekologi Manusia, Institut Pertanian \\ Bogor, Bogor 16680. Telp: 0251-8621258; Fax: 0251-8622276 \\ 2 Departemen Gizi Masyarakat, Fakultas Ekologi Manusia, Institut Pertanian Bogor, Bogor 16680.
}

\section{ABSTRACT}

The objective of this study was to know the correlation between nutrition and health knowledge, behavior of healthy life, and physical characteristic of the house towards health sighs of public transportation driver. Design of this study was a cross sectional study. The criterions of sample were (1) driver of Kampus Dalam and Leuwiliang route; (2) man; (3) age more than 30 years old; (4) had been worked as public transportation driver more than 2 years; (5) can communicate and ready for having an interview. The amount of sample is 60 respondents. The type of data was primary and secondary data. The primary data (individual and family characteristic, nutrition and health knowledge, life style, pattern of food consumption, behavior of healthy life, physical characteristic of the house, and health sighs of the driver) was collected by structural questionnaire interview. The body weight and height data were collected by direct measurement on the study sites. The secondary data had been obtained from "Dinas Perhubungan" of Bogor District. This study showed that nutrition and health knowledge, behavior of healthy life, and physical characteristic of the house did not correlate to health sighs of the public transportation driver. The correlation was analyzed by Spearman's correlation.

Key words: nutrition, healthy life, physical characteristic of house.

\section{PENDAHULUAN}

Data UNDP tahun 2007 mencatat bahwa Indeks Pembangunan Manusia (Human Development Indexs) di Indonesia masih belum memuaskan, yaitu menempati urutan ke 107 dari 177 negara. Martianto (2007) menyatakan bahwa indikator Indeks Pembangunan Manusia adalah pendidikan, ekonomi, dan kesehatan. Derajat kesehatan dipengaruhi oleh empat faktor penentu yaitu: faktor bawaan, pelayanan kese hatan, perilaku dan faktor lingkungan. Masalah-masalah kesehatan dipengaruhi oleh banyak faktor seperti sosial budaya, ekonomi, dan pendidikan (Sianipar 2007). Sehat merupakan investasi untuk meningkatkan produktivitas kerja guna meningkatkan kesejahteraan keluarga. Karena itu kesehatan perlu dijaga dan ditingkatkan oleh setiap individu. Perbaikan kondisi kesehatan dan status gizi seseorang dapat dipengaruhi oleh beberapa faktor, seperti pendidikan, pengetahuan gizi dan kesehatan, tingkat ekonomi, perilaku hidup sehat, dan lingkungan, termasuk ketersediaan sanitasi, air bersih, dan udara bersih.

Kesehatan merupakan hak setiap manusia, termasuk sopir angkot. Sopir angkot adalah orang yang pekerjaannya mengendarai angkutan umum (angkot) yang setiap harinya memiliki risiko terkena dampak negatif pencemaran (polusi) udara. Sopir angkot trayek Kampus Dalam dan Leuwiliang merupakan salah satu dari sekian banyak sopir dengan trayek lain yang diduga dapat terkena dampak negatif pencemaran udara. Sebuah penelitian menunjukkan bahwa orang yang berprofesi sebagai sopir mengalami lebih sering sakit kepala, sukar konsentrasi, pelupa, dan matanya terasa pekat serta perih (iritasi) (Soemarwoto, 2004).

Adanya berbagai penyakit yang mungkin diderita oleh sopir angkot ini akan semakin buruk dampaknya bila tidak disertai dengan penerapan perilaku hidup sehat dan upaya menjaga kesehatan lingkungan dalam kehidupan sehari-hari. Berdasarkan hal-hal di atas, 
penulis tertarik untuk melakukan penelitian tentang hubungan pengetahuan gizi dan kesehatan, perilaku hidup sehat, serta karakteristik lingkungan fisik rumah terhadap keluhan kesehatan pada sopir angkot di Kabupaten Bogor, khususnya trayek Kampus Dalam dan Leuwiliang.

Secara umum penelitian ini bertujuan untuk mengetahui hubungan pengetahuan gizi dan kesehatan, perilaku hidup sehat, serta karakteristik lingkungan fisik rumah terhadap keluhan kesehatan sopir angkot di Kabupaten Bogor. Tujuan khususnya adalah (1) mengidentifikasi karakteristik individu dan keluarga contoh, (2) mengetahui pengetahuan gizi dan kesehatan contoh, (3) mengetahui gaya hidup, pola konsumsi pangan, dan perilaku hidup sehat contoh, (4) mengetahui karakteristik lingkungan fisik rumah contoh, (5) mempelajari keluhan kesehatan dan status gizi contoh, (6) menganalisis hubungan pengetahuan gizi dan kesehatan, perilaku hidup sehat, dan karakteristik lingkungan fisik rumah terhadap keluhan kesehatan contoh, (7) menganalisis hubungan keluhan kesehatan terhadap status gizi contoh.

\section{METODE PENELITIAN}

\section{Desain, Tempat, dan Waktu Penelitian}

Desain penelitian adalah cross sectional study. Penelitian dilaksanakan di Terminal Bubulak dan Terminal Laladon, Kabupaten Bogor. Tempat penelitian ditentukan secara purposive, dengan pertimbangan daerah tersebut merupakan sentral sopir angkot berkumpul dan menunggu giliran jalan. Waktu penelitian (pengumpulan infomasi dan data) berlangsung selama 1 bulan yaitu pada bulan Maret 2008.

\section{Jumlah dan Cara Penarikan Contoh}

Contoh penelitian ini adalah sopi angkot Trayek Kampus Dalam dan Leuwiliang. Cara pengambilan contoh dilakukan dengan purposive sampling, dengan menggunakan kriteria 1) laki-laki; 2) berusia >30 tahun; 3) bekerja sebagai sopir angkot >2 tahun; 4) dapat berkomunikasi dengan baik dan bersedia diwawancarai. Jumlah contoh yang diteliti sebanyak 30 sopir pada Trayek Kampus Dalam dan 30 sopir pada Trayek Leuwiliang yang diambil sesuai dengan kriteria, sehingga diperoleh total contoh sebanyak 60 sopir.

\section{Jenis dan Cara Pengumpulan Data}

Data yang dikumpulkan terdiri dari data primer dan data sekunder. Jenis dan cara pengumpulan data primer dapat dilihat pada Tabel 1. Data sekunder yang dikumpulkan berupa data jumlah trayek dan jumlah angkot yang beroperasi di Kabupaten Bogor yang diperoleh dari Dinas Lalu Lintas Angkutan Jalan (DLLAJ) Kabupaten Bogor. Data berat badan dan tinggi badan contoh diperoleh melalui pengukuran langsung oleh peneliti di tempat pengambilan data primer.

\section{Pengolahan dan Analisis Data}

Data yang diperoleh, diolah dan dianalisis secara statistik deskriptif dengan bantuan program Microsoft Excell dan SPSS for windows versi 13.0. Hubungan antara variabel kategorik dianalisis secara statistik dengan menggunakan Rank Spearman Correlation Test. Uji beda Mann-Whitney digunakan untuk menguji signifikansi perbedaan antara karakteristik individu dan keluarga, pengetahuan gizi dan kesehatan, gaya hidup, perilaku hidup sehat, karakteristik lingkungan fisik rumah, keluhan kesehatan dan status gizi contoh antara sopir Kampus Dalam dengan sopir Leuwiliang. Cara pengkategorian dan analisis variabel disajikan pada Tabel 2 .

\section{HASIL DAN PEMBAHASAN}

\section{Karakteristik Contoh}

\section{Umur}

Lebih dari separuh contoh (53.3\%) tergolong pada masa dewasa awal, dan hanya $5 \%$ yang tergolong dewasa akhir. Pada trayek Kampus Dalam, masih ada $10 \%$ contoh sopir yang termasuk dalam kelompok masa dewasa akhir, sedangkan pada trayek Leuwiliang, tidak ada sopir yang termasuk dalam kelompok masa dewasa akhir. Hal ini diduga karena jarak tempuh pada Trayek Leuwiliang lebih jauh daripada jarak tempuh pada Trayek Kampus Dalam, sehingga tidak ada contoh pada sopir Leuwiliang yang tergolong kategori dewasa akhir yang masih kuat untuk mengendarai angkot. Sebaran contoh berdasarkan umur disajikan pada Tabel 3.

Pada masa dewasa akhir, terjadi banyak sekali penurunan kemampuan individu, baik secara fisik maupun psikis (Faiz 2008). Selain itu, Palestin (2006) menyatakan bahwa proses 
Tabel 1. Jenis dan Cara Pengumpulan Data Primer

\begin{tabular}{|c|c|c|}
\hline Variabel & Data yang dikumpulkan & $\begin{array}{l}\text { Cara pengumpulan } \\
\text { data }\end{array}$ \\
\hline $\begin{array}{l}\text { 1. Karakteristik Individu } \\
\text { dan Keluarga Contoh }\end{array}$ & $\begin{array}{l}\text { 1. Umur } \\
\text { 2. Pendidikan } \\
\text { 3. Pendapatan } \\
\text { 4. Besar keluarga }\end{array}$ & Wawancara (Kuesioner) \\
\hline $\begin{array}{l}\text { 2. Pengetahuan } \\
\text { Gizi dan Kesehatan }\end{array}$ & $\begin{array}{l}\text { 1. Definisi zat gizi } \\
\text { 2. Pangan sumber zat gizi } \\
\text { 3. Dampak kekurangan zat gizi } \\
\text { 4. Kesehatan fisik } \\
\text { 5. Kesehatan psikis } \\
\text { 6. Kesehatan lingkungan }\end{array}$ & Wawancara (Kuesioner) \\
\hline 3. Gaya Hidup & $\begin{array}{l}\text { 1. Kebiasaan olahraga } \\
\text { 2. Kebiasaan merokok } \\
\text { 3. Kebiasaa konsumsi alkohol }\end{array}$ & Wawancara (Kuesioner) \\
\hline 4. Pola Makan & $\begin{array}{l}\text { 1. Kebiasaan makan } \\
\text { 2. Frekuensi konsumsi jenis pangan }\end{array}$ & Wawancara (Kuesioner) \\
\hline 5. Perilaku Hidup Sehat & $\begin{array}{l}\text { 1. Kebiasaan mandi } \\
\text { 2. Menggosok gigi } \\
\text { 3. Keramas } \\
\text { 4. Cuci tangan } \\
\text { 5. Gunting kuku } \\
\text { 6. Memakai alas kaki } \\
\text { 7. Pemakaian handuk } \\
\text { 8. Kebiasaan ganti baju }\end{array}$ & Wawancara (Kuesioner) \\
\hline $\begin{array}{l}\text { 6. Karakteristik } \\
\text { Lingkungan } \\
\text { Fisik Rumah }\end{array}$ & $\begin{array}{l}\text { 1. Status rumah } \\
\text { 2. Struktur bangunan rumah } \\
\text { 3. Sumber air bersih } \\
\text { 4. Kepemilikan kamar mandi dan WC } \\
\text { 5. Tempat pembuangan sampah/kotoran } \\
\text { 6. Letak kandang }\end{array}$ & Wawancara (Kuesioner) \\
\hline 7. Status Gizi & $\begin{array}{l}\text { 1. Berat badan }(\mathrm{kg}) \\
\text { 2. Tinggi badan }(\mathrm{cm}) \\
\text { IMT }\left(\mathrm{kg} / \mathrm{m}^{2}\right)\end{array}$ & $\begin{array}{l}\text { BB diukur dengan } \\
\text { bathroom scale }(\mathrm{kg}) \\
\text { TB diukur dengan } \\
\text { microtoise }(\mathrm{cm})\end{array}$ \\
\hline 8. Keluhan Kesehatan & 1. Frekuensi dan jenis keluhan sakit & Wawancara (Kuesioner) \\
\hline
\end{tabular}

penuaan berhubungan dengan kemunduran kapasitas fisiologis, misalnya kekuatan otot, kapasitas aerobik, koordinasi neuromotorik, dan fleksibilitas. peningkatan disabilitas fungsional yang terkait dengan usia tersebut memiliki risiko terhadap aktivitas fisik yang terbatas.

\section{Pendidikan}

Tingkat pendidikan formal yang pernah ditempuh contoh sebesar $36.7 \%$ adalah SLTA/ sederajat. Tingkat pendidikan sopir Leuwiliang lebih baik daripada sopir Kampus Dalam. Pada sopir Leuwiliang, persentase terbesar contoh (40\%) memiliki tingkat pendidikan SLTA/sederajat. Sedangkan pada sopir Kampus Dalam, yang memiliki tingkat pendidikan SLTA/sederajat sama persentasenya dengan yang memiliki tingkat pendidikan SD/sederajat (33.3\%). Sebaran contoh berdasarkan tingkat pendidikan dapat dilihat pada Tabel 4.

\section{Karakteristik Sosial Ekonomi Keluarga}

\section{Besar Keluarga}

Separuh contoh termasuk dalam kategori keluarga kecil. Pada sopir Kampus Dalam, lebih dari separuh contoh (60\%) termasuk dalam kategori keluarga kecil, Sedangkan pada sopir Leuwiliang, persentase keluarga kecil dan sedang adalah sama, yaitu sebesar $40 \%$. Sebaran contoh berdasarkan besar keluarga dapat dilihat pada Tabel 5.

\section{Pendapatan Per kapita}

Lebih dari separuh contoh tergolong dalam kategori keluarga tidak miskin. Jumlah kelompok keluarga miskin pada contoh sopir Kampus Dalam lebih banyak daripada sopir Leuwiliang. Sebaran contoh berdasarkan pendapatan perkapita dapat dilihat pada Tabel 6 . 
Tabel 2. Cara Pengkategorian dan Analisis Variabel Penelitian

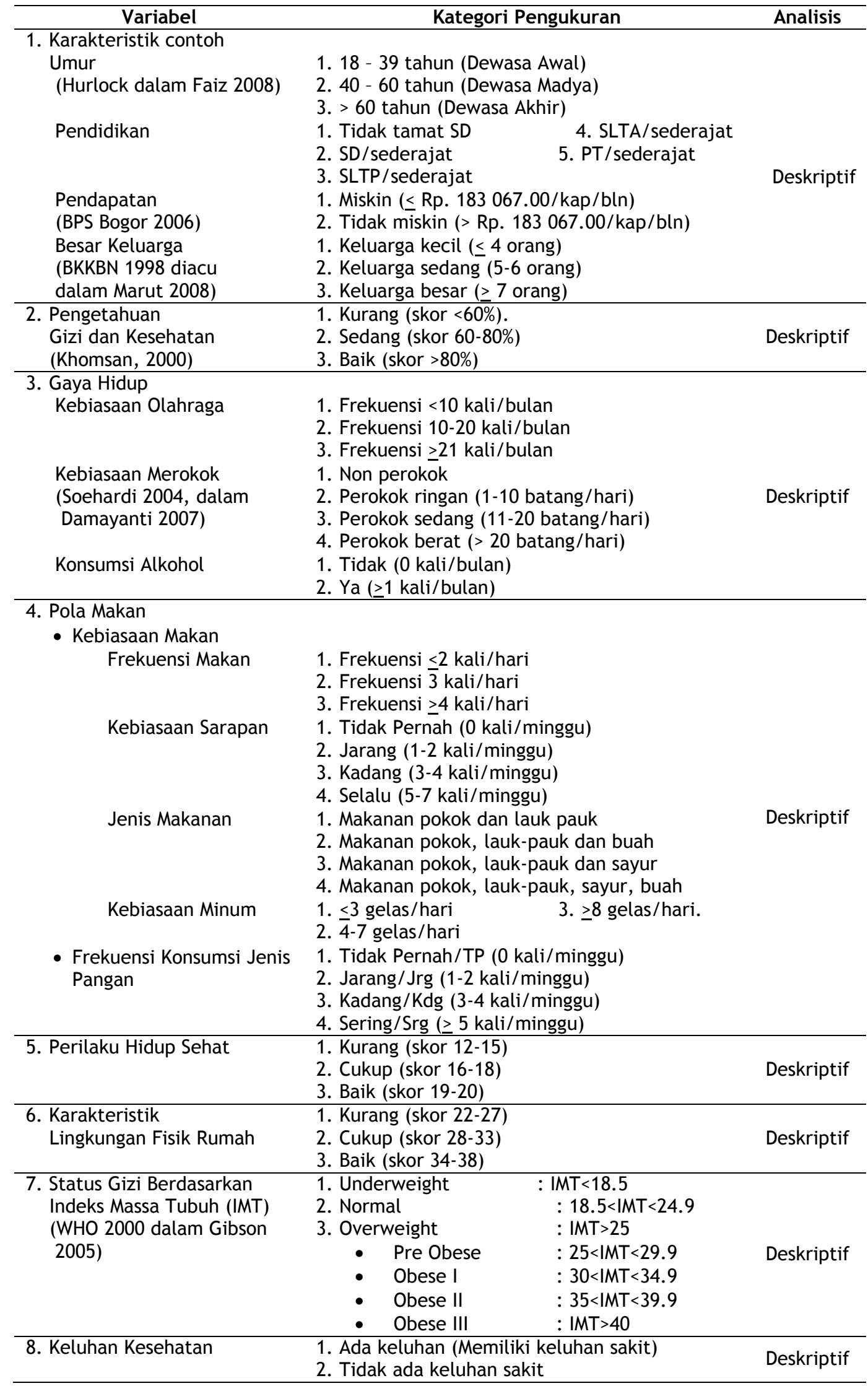


Tabel 3. Sebaran Contoh berdasarkan Umur

\begin{tabular}{lcccccc}
\hline \multirow{2}{*}{ Kategori Umur } & \multicolumn{2}{c}{ Sopir Kampus Dalam } & \multicolumn{2}{c}{ Sopir Leuwiliang } & \multicolumn{2}{c}{ Total } \\
\cline { 2 - 7 } & $\mathrm{N}$ & $\%$ & $\mathrm{~N}$ & $\%$ & $\mathrm{n}$ & $\%$ \\
\hline Dewasa Awal (18-39 Tahun) & 16 & 53.3 & 16 & 53.3 & 32 & 53.3 \\
Dewasa Madya(40-60 Tahun) & 11 & 36.7 & 14 & 46.7 & 25 & 41.7 \\
Dewasa Akhir (>60 Tahun) & 3 & 10.0 & 0 & 0.0 & 3 & 5.0 \\
\hline Total & 30 & 100 & 30 & 100 & 60 & 100 \\
\hline
\end{tabular}

Tabel 4. Sebaran Contoh berdasarkan Tingkat Pendidikan

\begin{tabular}{lcccccc}
\hline \multirow{2}{*}{ Tingkat Pendidikan } & \multicolumn{2}{c}{ Sopir Kampus Dalam } & \multicolumn{2}{c}{ Sopir Leuwiliang } & \multicolumn{2}{c}{ Total } \\
\cline { 2 - 7 } & $\mathbf{n}$ & $\%$ & $\mathbf{n}$ & $\%$ & $\mathbf{n}$ & $\%$ \\
\hline Tidak Tamat SD & 2 & 6.7 & 0 & 0.0 & 2 & 3.3 \\
SD/sederajat & 10 & 33.3 & 8 & 26.7 & 18 & 30.0 \\
SLTP/sederajat & 8 & 26.7 & 9 & 30.0 & 17 & 28.3 \\
SLTA/sederajat & 10 & 33.3 & 12 & 40.0 & 22 & 36.7 \\
PT/sederajat & 0 & 0.0 & 1 & 3.3 & 1 & 1.7 \\
\hline Total & $\mathbf{3 0}$ & $\mathbf{1 0 0}$ & $\mathbf{3 0}$ & $\mathbf{1 0 0}$ & $\mathbf{6 0}$ & $\mathbf{1 0 0}$ \\
\hline
\end{tabular}

Menurut Sumarwan (2004), pendapatan yang diukur biasanya bukan hanya berasal dari pendapatan yang diterima oleh seorang individu, tetapi diukur juga dari pendapatan yang diterima oleh semua anggota keluarga dimana individu itu berada. Lebih banyaknya jumlah keluarga miskin pada contoh sopir Kampus Dalam diduga karena lebih dari separuh contoh pada sopir Kampus Dalam termasuk dalam kategori keluarga kecil, sehingga pemasukan dari anggota keluarga pun tidak terlalu banyak, meskipun rata-rata pendapatan per bulan sopir Kampus Dalam lebih besar daripada pendapatan per bulan sopir Leuwiliang.

Lebih banyaknya jumlah keluarga yang tidak miskin pada sopir Leuwiliang diduga berhubungan dengan tingkat pendidikan, dimana contoh pada sopir Leuwiliang memiliki tingkat pendidikan yang lebih baik. Contoh yang memiliki tingkat pendidikan lebih baik memiliki tingkat pendapatan yang lebih baik pula. Hal ini didukung dengan hasil uji korelasi Spearman yang menunjukkan bahwa tingkat pendidikan berhubungan positif dan signifikan dengan pendapatan contoh $(r=0.257, p=0.047)$. Tyler dalam Hidayat (2008) mengungkapkan bahwa pendidikan dapat mempengaruhi tingkat pendapatan.

\section{Pengetahuan Gizi dan Kesehatan}

Separuh contoh memiliki tingkat pengetahuan gizi dan kesehatan yang tinggi. Baik pada sopir Kampus Dalam maupun sopir Leuwiliang, yang memiliki tingkat pengetahuan gizi dan kesehatan yang masih rendah adalah sebesar 20\%. Sebaran contoh berdasarkan tingkat pengetahuan gizi dan kesehatan disajikan pada Tabel 7.

Tabel 5. Sebaran Contoh berdasarkan Besar Keluarga

\begin{tabular}{lcccccc}
\hline \multirow{2}{*}{ Besar Keluarga } & \multicolumn{2}{c}{ Sopir Kampus Dalam } & \multicolumn{2}{c}{ Sopir Leuwiliang } & \multicolumn{2}{c}{ Total } \\
\cline { 2 - 7 } & $\mathbf{n}$ & $\%$ & $\mathbf{n}$ & $\%$ & $\mathbf{n}$ & $\%$ \\
\hline Kecil ( $\leq$ 4 orang) & 18 & 60.0 & 12 & 40.0 & 30 & 50.0 \\
Sedang (5-6 orang) & 11 & 36.7 & 12 & 40.0 & 23 & 38.3 \\
Besar ( $\geq 7$ orang) & 1 & 3.3 & 6 & 20.0 & 7 & 11.7 \\
\hline Total & 30 & 100 & 30 & 100 & 60 & 100 \\
\hline
\end{tabular}

Tabel 6. Sebaran Contoh berdasarkan Pendapatan Per Kapita

\begin{tabular}{lcccccc}
\hline \multirow{2}{*}{$\begin{array}{c}\text { Pendapatan } \\
\text { Perkapita Per Bulan }\end{array}$} & \multicolumn{2}{c}{ Sopir Kampus Dalam } & Sopir Leuwiliang & \multicolumn{2}{c}{ Total } \\
\cline { 2 - 6 } & $\mathbf{n}$ & $\%$ & $\mathbf{n}$ & $\%$ & $\mathbf{n}$ & $\%$ \\
\hline Miskin $(<183.067 .00)$ & 14 & 46.7 & 11 & 36.7 & 25 & 41.7 \\
Tidak Miskin $(\geq 183.067 .00)$ & 16 & 53.3 & 19 & 63.3 & 35 & 58.3 \\
\hline Total & 30 & 100 & 30 & 100 & 60 & 100 \\
\hline
\end{tabular}


Tabel 7. Sebaran Contoh berdasarkan Tingkat Pengetahuan Gizi dan Kesehatan

\begin{tabular}{lcccccc}
\hline \multirow{2}{*}{$\begin{array}{c}\text { Tingkat Pengetahuan } \\
\text { Gizi dan Kesehatan }\end{array}$} & \multicolumn{2}{c}{ Sopir Kampus Dalam } & Sopir Leuwiliang & \multicolumn{2}{c}{ Total } \\
\cline { 2 - 6 } & $\mathbf{n}$ & $\%$ & $\mathbf{n}$ & $\%$ & $\mathbf{n}$ & $\%$ \\
\hline Rendah $(<60 \%)$ & 6 & 20.0 & 6 & 20.0 & 12 & 20.0 \\
Sedang $(60-80 \%)$ & 10 & 33.3 & 8 & 26.7 & 18 & 30.0 \\
Tinggi (>80\%) & 14 & 46.7 & 16 & 53.3 & 30 & 50.0 \\
\hline Total & 30 & 100 & 30 & 100 & 60 & 100 \\
\hline
\end{tabular}

Jika dibandingkan, tingkat pengetahuan gizi dan kesehatan yang tinggi pada sopir Leuwiliang lebih banyak persentasenya daripada sopir Kampus Dalam. Hal ini diduga berkaitan pula dengan tingkat pendidikan pada sopir Leuwiliang yang relatif lebih tinggi. Uji korelasi Spearman menunjukkan bahwa terdapat hubungan yang positif dan sangat signifikan antara tingkat pendidikan dengan pengetahuan gizi dan kesehatan contoh $\left(r=0.394^{* *}\right.$, $\mathrm{p}=0.002$ ). Hal ini berarti bahwa tingkat pendidikan seseorang sangat berhubungan dengan pengetahuan gizi dan kesehatan.

Pertanyaan mengenai pengetahuan gizi dan kesehatan yang masih sedikit contoh menjawab dengan benar adalah mengenai akibat yang ditimbulkan bila tubuh kekurangan iodium. Lebih dari separuh contoh $(60 \%)$ menjawab bahwa bila tubuh kekurangan yodium, maka akan menyebabkan gondok saja, sedangkan yang menjawab gondok dan pertumbuhan terhambat sebesar $23.3 \%$ contoh.

Lebih dari separuh contoh dapat menjawab dengan benar pertanyaan mengenai akibat yang ditimbulkan akibat kebiasaan merokok. Namun pada kenyataannya, sebagian besar contoh justru memiliki kebiasaan merokok. Uji korelasi Spearman menunjukkan bahwa pengetahuan mengenai bahaya merokok berhubungan positif dan tidak signifikan dengan kebiasaan merokok $(r=0.243, p>0.05)$. Hal ini berarti terdapat kecenderungan dimana pengetahuan mengenai bahaya merokok yang baik belum tentu diikuti dengan kesadaran contoh untuk berhenti merokok.

\section{Gaya Hidup}

\section{Olahraga}

Lebih dari separuh contoh (68.3\%) memiliki kebiasaan olahraga. Persentase contoh yang biasa berolahraga pada sopir Kampus Dalam (83.3\%) lebih besar daripada sopir Leuwiliang (53.3\%). Jenis olahraga yang paling sering dilakukan oleh contoh adalah lari (43.9\%), sepakbola (36.6\%), bulutangkis (29.3\%), dan te nis meja (24.4\%). Olahraga tenis meja biasanya dilakukan contoh di Terminal Bubulak, ketika menunggu giliran jalan, karena di terminal tersebut sudah tersedia fasilitas untuk bermain tenis meja.

\section{Merokok}

Sebagian besar contoh (86.7\%) dalam penelitian ini memiliki kebiasaan merokok. Hanya 23.3\% contoh pada sopir Kampus Dalam dan 3.3\% contoh pada sopir Leuwiliang yang tidak merokok. Hasil uji beda Mann-Whithney menunjukkan bahwa kebiasaan merokok pada sopir Kampus Dalam dan sopir Leuwiliang berbeda nyata. Kebiasaan merokok bukan saja merugikan perokok itu sendiri melainkan bagi orang di sekitarnya. Asap rokok merupakan polutan bagi manusia dan lingkungan sekitarnya. Bukan hanya bagi kesehatan, merokok menimbulkan problem pula di bidang ekonomi. Di negara industri maju, kini terdapat kecenderungan berhenti merokok, sedangkan di negara berkembang, khususnya Indonesia, malah cenderung timbul peningkatan kebiasaan merokok (Tandra, 2006).

Sebanyak $27.6 \%$ contoh sopir Leuwiliang mulai merokok pada usia $\leq 15$ tahun. Berdasarkan usia mulai merokok, lebih dari separuh contoh (60\%) yang merokok $\leq 15$ tahun adalah contoh yang tergolong masa dewasa awal. Aktivitas merokok tidak hanya banyak di kalangan dewasa namun sejak usia remaja pun sudah cukup banyak yang sudah merokok. Merokok adalah kebiasaan jelek yang mengakibatkan berbagai macam penyakit. Ironisnya kebiasaan merokok (di Indonesia), seolah-olah sudah membudaya. Berdasarkan hasil penelitian, sekitar $15 \%$ remaja di Indonesia telah merokok (Notoatmodjo, 2007). Hal ini perlu mendapat perhatian dan tindakan yang serius, karena aktivitas merokok dapat mengganggu kesehatan, bahkan seorang perokok mempunyai tingkat kematian 70\% lebih tinggi akibat penyakit jantung koroner dibanding yang tidak merokok (Kusnoputranto, 1995).

\section{Konsumsi Alkohol}

Hasil penelitian menunjukkan bahwa contoh yang memiliki kebiasaan mengkonsumsi alkohol sebanyak $15 \%$. Jumlah contoh yang 
biasa minum alkohol lebih banyak pada sopir Leuwiliang (23.3\%) daripada sopir Kampus Dalam (6.7\%). Jumlah contoh yang biasa mengonsumsi alkohol relatif besar dan dikhawatirkan akan menjadi budaya bila tidak segera ditangani. Notoatmodjo (2007) menyatakan bahwa sekitar $1 \%$ penduduk Indonesia dewasa diperkirakan sudah mempunyai kebiasaan minum alkohol.

Alkohol dapat berpengaruh negatif bagi kesehatan manusia jika dikonsumsi secara tidak wajar dan terus-menerus. Pengaruh alkohol dapat dirasakan oleh seluruh anggota tubuh, dari yang paling atas sampai yang paling bawah. Oleh karena itu, yang paling awal terpengaruh adalah sel-sel keinginan dan kendali diri. Selain terhadap otak, alkohol juga dapat berpengaruh negatif terhadap jantung dan pembuluh darah, sel-sel darah, serta hati (liver) (As-Sayyid 2006). Alkohol yang dikonsumsi secara berlebihan dapat meningkatkan tekanan darah (Wirakusumah 2001).

\section{Pola Konsumsi Pangan}

\section{Frekuensi Makan}

Lebih dari separuh contoh (51.7\%) mempunyai kebiasaan makan 3 kali dalam sehari. Pada sopir Kampus Dalam sebanyak 43.3\% contoh memiliki frekuensi makan 2 kali sehari, diduga berkaitan dengan pendapatan perkapita yang relatif lebih rendah daripada sopir Leuwiliang. Sumarwan (2004) menyatakan bahwa jumlah pendapatan menggambarkan besarnya daya beli seseorang. Contoh yang biasa makan 2 kali sehari biasanya makan pada waktu siang dan sore atau siang dan malam. Sedangkan contoh yang biasa makan 4 kali dalam sehari biasanya waktu makannya adalah pagi, siang, sore, dan malan. Sebaran contoh berdasarkan frekuensi makan dapat dilihat pada Tabel 8.

Menurut Khomsan (2002), frekuensi makan yang baik adalah tiga kali sehari. Secara kuantitas dan kualitas sulit untuk memenuhi kebutuhan gizi apabila frekuensi makannya hanya 1 kali atau 2 kali sehari. Keterbatasan volume lambung menyebabkan tubuh tidak bisa menerima makanan sekaligus dalam jumlah yang banyak. Itulah sebabnya makan dilakukan secara frekuentif yakni 3 kali sehari.

\section{Kebiasaan Sarapan}

Lebih dari separuh contoh (68.3\%) selalu sarapan pagi. Contoh yang tidak pernah sarapan pagi sebanyak $11.7 \%$. Pada kedua kelompok, persentase contoh yang selalu sarapan lebih banyak daripada yang tidak pernah sarapan. Menurut Khomsan (2002), Sarapan pagi dapat menyediakan karbohidrat yang siap digunakan untuk meningkatkan kadar gula darah dan memberikan kontribusi penting akan zat gizi yang diperlukan tubuh seperti protein, lemak, vitamin, dan mineral.

\section{Jenis Makanan}

Sebanyak 70\% contoh mengonsumsi makanan pokok, lauk pauk, dan sayuran. Semakin bervariasinya susunan hidangan yang dikonsumsi contoh, maka zat gizi yang diperoleh semakin baik. Contoh yang mengonsumsi jenis makanan yang lengkap seperti makanan pokok, lauk pauk, sayuran, dan buah-buahan masih relatif sedikit yaitu $6.7 \%$ pada sopir Kampus Dalam dan 33.3\% pada sopir Leuwiliang. Hal ini diduga terkait dengan pendapatan sopir yang terbatas sehingga contoh membatasi diri dalam mengkonsumsi jenis makanan.

\section{Kebiasaan Minum Air Putih}

Lebih dari separuh contoh memiliki kebiasaan minum air putih $\geq 8$ gelas per hari. Meskipun demikian, masih ada sebesar $3.3 \%$ contoh yang minum air putih $\leq 3$ gelas per hari. Sebaran contoh berdasarkan kebiasaan minum air putih disajikan pada Tabel 9.

Masih adanya contoh yang minum $\leq 3$ gelas per hari karena mereka minum air ketika merasa haus saja atau ketika selesai makan. Padahal, persediaan air yang cukup dalam tubuh sangat dibutuhkan oleh organ-organ tubuh dalam menjalankan tugasnya sebagai bagian dari sistem hidup kita. Ketersediaan air dalam

Tabel 8. Sebaran contoh Berdasarkan Frekuensi Makan per Hari

\begin{tabular}{ccccccc}
\hline \multirow{2}{*}{$\begin{array}{c}\text { Frekuensi Makan } \\
\text { (Kali/hari) }\end{array}$} & \multicolumn{2}{c}{ Sopir Kampus Dalam } & \multicolumn{2}{c}{ Sopir Leuwiliang } & \multicolumn{2}{c}{ Total } \\
\cline { 2 - 7 } & $\mathbf{N}$ & $\%$ & $\mathbf{n}$ & $\%$ & $\mathbf{n}$ & $\%$ \\
\hline 2 & 13 & 43.3 & 11 & 36.7 & 24 & 40.0 \\
3 & 14 & 46.7 & 17 & 56.7 & 31 & 51.7 \\
4 & 3 & 10.0 & 2 & 6.6 & 5 & 8.3 \\
\hline Total & 30 & 100 & 30 & 100 & 60 & 100 \\
\hline
\end{tabular}


Tabel 9. Sebaran Contoh berdasarkan Kebiasaan Minum Air Putih

\begin{tabular}{cccccccc}
\hline \multirow{2}{*}{$\begin{array}{c}\text { Kebiasaan Minum } \\
\text { Air Putih (gelas/hari) }\end{array}$} & \multicolumn{2}{c}{ Sopir Kampus Dalam } & Sopir Leuwiliang & \multicolumn{2}{c}{ Total } \\
\cline { 2 - 7 } & $\mathbf{n}$ & $\%$ & $\mathbf{n}$ & $\%$ & $\mathbf{n}$ & $\%$ \\
\hline $4-7$ & 1 & 3.3 & 1 & 3.3 & 2 & 3.3 \\
& 13 & 43.4 & 13 & 43.4 & 26 & 43.4 \\
& 28 & 16 & 53.3 & 16 & 53.3 & 32 & 53.3 \\
\hline Total & 30 & 100 & 30 & 100 & 60 & 100 \\
\hline
\end{tabular}

tubuh sangat vital perannya dalam proses pencernaan dan metabolisme. Dalam kedua proses ini, air akan mengangkut vitaminvitamin dan oksigen untuk sel-sel tubuh melalui darah (Luize 2003). Emoto (2006) menyatakan bahwa dengan mengkonsumsi air yang ba$i k$, seseorang dapat mempertahankan kesehatannya. Menurut Dr Howard Flaks diacu dalam Luize (2003), air yang perlu diminum oleh orang sehat adalah sebanyak 8 sampai 10 gelas air setiap hari. Jumlah ini masih ditambah jika seseorang banyak melakukan latihan olahraga atau hidup di daerah beriklim panas.

\section{Perilaku Hidup Sehat}

Berdasarkan perilaku hidup sehat, hampir separuh contoh termasuk dalam kategori cukup. Sebesar $6.6 \%$ contoh pada sopir Leuwiliang masih tergolong dalam kategori kurang, sedangkan lebih dari separuh contoh pada sopir Kampus Dalam termasuk dalam kategori baik. Nilai perilaku hidup sehat contoh yang baik diharapkan dapat mencerminkan kondisi kesehatan contoh, karena dengan perilaku hidup yang sehat berarti telah melakukan usaha pencegahan terhadap penularan berbagai penyakit infeksi (Nurwulan 2003). Sebaran contoh berdasarkan kategori perilaku hidup sehat disajikan pada Tabel 10.

Perilaku hidup sehat contoh yang masih tergolong kurang penerapannya dalam kehidupan sehari-hari adalah mencuci tangan sebelum makan menggunakan air bersih dan sabun serta menggunting kuku minimal seminggu sekali. Mencuci tangan dengan air bersih dan sabun dapat membunuh beberapa bakteri penyebab penyakit (WHO 1988), namun tidak semua contoh dapat mempraktikkannya. Terkadang contoh sudah merasa cukup mencuci tangan hanya dengan menggunakan air saja. Adapun perilaku hidup sehat yang selalu dilakukan oleh seluruh contoh adalah menggosok gigi dengan menggunakan pasta gigi.

\section{Karakteristik Lingkungan Fisik Rumah}

Lebih dari separuh contoh (61.7\%) berada pada kategori lingkungan fisik rumah baik. Pada contoh sopir Leuwiliang sebesar 46.7\% masih berada pada kategori lingkungan fisik rumah cukup. Adapun sebaran contoh berdasarkan kategori lingkungan fisik rumah dapat dilihat pada Tabel 11 .

Tabel 10. Sebaran Contoh berdasarkan Kategori Perilaku Hidup Sehat

\begin{tabular}{lcccccc}
\hline \multirow{2}{*}{$\begin{array}{c}\text { Kategori } \\
\text { Perilaku Hidup Sehat }\end{array}$} & \multicolumn{2}{c}{$\begin{array}{c}\text { Sopir } \\
\text { Kampus Dalam }\end{array}$} & \multicolumn{2}{c}{ Sopir } & \multicolumn{2}{c}{ Total } \\
\cline { 2 - 7 } & $\mathbf{n}$ & $\%$ & $\mathbf{n}$ & $\%$ & $\mathbf{n}$ & $\%$ \\
\hline Kurang (12-15) & 1 & 3.3 & 2 & 6.6 & 3 & 5.0 \\
Cukup (16-18) & 13 & 43.4 & 14 & 46.7 & 27 & 45.0 \\
Baik (19-20) & 16 & 53.3 & 14 & 46.7 & 30 & 50.0 \\
\hline Total & 30 & 100 & 30 & $\mathbf{1 0 0}$ & $\mathbf{6 0}$ & 100 \\
\hline
\end{tabular}

Tabel 11. Sebaran Contoh berdasarkan Kategori Lingkungan Fisik Rumah

\begin{tabular}{lcccccc}
\hline \multirow{2}{*}{$\begin{array}{c}\text { Kategori } \\
\text { Lingkungan Fisik Rumah }\end{array}$} & \multicolumn{2}{c}{$\begin{array}{c}\text { Sopir } \\
\text { Kampus Dalam }\end{array}$} & \multicolumn{2}{c}{$\begin{array}{c}\text { Sopir } \\
\text { Leuwiliang }\end{array}$} & \multicolumn{2}{c}{ Total } \\
\cline { 2 - 7 } & $\mathbf{n}$ & $\%$ & $\mathbf{n}$ & $\%$ & $\mathbf{n}$ & $\%$ \\
\hline Kurang (22-27) & 1 & 3.3 & 1 & 3.3 & 2 & 3.3 \\
Cukup (28-33) & 13 & 43.3 & 14 & 46.7 & 27 & 45.0 \\
Baik (34-38) & 16 & 53.4 & 15 & 50.0 & 31 & 51.7 \\
\hline Total & $\mathbf{3 0}$ & $\mathbf{1 0 0}$ & $\mathbf{3 0}$ & $\mathbf{1 0 0}$ & $\mathbf{6 0}$ & $\mathbf{1 0 0}$ \\
\hline
\end{tabular}


Lingkungan fisik rumah yang belum baik ditunjukkan dengan masih adanya sebanyak 23.3\% contoh yang tidak memiliki WC (jamban), sehingga contoh dan keluarganya membuang hajat di sungai/empang. Nurwulan (2003) menyatakan bahwa kelengkapan fasilitas pokok suatu rumah ikut menentukan nyaman atau tidaknya suatu rumah, juga menentukan kualitas suatu rumah. Fasilitas pokok yang penting agar suatu rumah menjadi sehat dan nyaman adalah tersedianya sarana sanitasi berupa jamban keluarga. Selain itu, lebih dari separuh contoh (56.7\%) membuang sampah di lubang terbuka/sungai. Pemanfaatan sungai sebagai sarana pembuangan sampah sudah sangat lazim di lingkungan penduduk karena kepraktisannya, padahal dampak yang diakibatkan oleh kebiasaan yang salah ini sangat besar, terutama terhadap timbulnya berbagai penyakit, polusi, dan banjir.

\section{Keluhan Kesehatan}

Berdasarkan hasil penelitian, lebih dari separuh contoh memiliki keluhan kesehatan selama satu bulan terakhir. Contoh yang berada dalam keadaan sehat (tidak memiliki keeluhan kesehatan) sebesar $33.3 \%$. Notoatmodjo (2007) menyatakan bahwa indikator kesehatan individu adalah bebas dari penyakit/tidak sakit, tidak cacat, dan produktif. Jumlah contoh yang memiliki keluhan kesehatan selama satu bulan terakhir pada sopir Leuwiliang lebih ba- nyak (73.3\%) daripada sopir Kampus Dalam (60\%). Sebaran contoh berdasarkan ada tidaknya keluhan kesehatan dapat dilihat pada Tabel 12.

\section{Jenis Keluhan}

Sebanyak $31.7 \%$ contoh mengeluh pusing/sakit kepala selama satu bulan terakhir. Persentase contoh yang pusing/sakit kepala pada sopir Leuwiliang lebih banyak (40\%) dari pada sopir Kampus Dalam (23.3\%). Sebuah penelitian menunjukkan bahwa orang yang berprofesi sebagai sopir mengalami lebih sering sakit kepala, sukar konsentrasi, pelupa, dan matanya terasa pekat serta perih (iritasi) (Soemarwoto 2004). Jenis keluhan yang cukup banyak pada sopir Kampus Dalam adalah batuk (16.7\%) dan flu (16.7\%). Demam/masuk angin merupakan jenis keluhan yang cukup banyak terjadi pada sopir Leuwiliang (13.3\%).

Pada sopir Leuwiliang terdapat 3.3\% contoh yang menderita gangguan tekanan darah (hipertensi). Menurut Ramaiah (2007), faktor risiko hipertensi diantaranya adalah diabetes, merokok, kolesterol tinggi, usia tua, pria, dan riwayat serangan jantung pada keluarga. Selain itu, seseorang dengan gaya hidup yang tidak banyak bergerak memiliki risiko 20 $50 \%$ lebih besar terkena hipertensi. Sebaran contoh berdasarkan jenis keluhan sakit selama 1 bulan terakhir disajikan pada Tabel 13 .

Tabel 12. Sebaran Contoh berdasarkan Keluhan Kesehatan Selama 1 Bulan Terakhir

\begin{tabular}{lcccccc}
\hline \multirow{2}{*}{ Keluhan Kesehatan } & \multicolumn{2}{c}{ Sopir Kampus Dalam } & \multicolumn{2}{c}{ Sopir Leuwiliang } & \multicolumn{2}{c}{ Total } \\
\cline { 2 - 7 } & $\mathbf{n}$ & $\%$ & $\mathbf{n}$ & $\%$ & $\mathbf{N}$ & $\%$ \\
\hline Ada Keluhan & 18 & 60.0 & 22 & 73.3 & 40 & 66.7 \\
Tidak Ada Keluhan & 12 & 40.0 & 8 & 26.7 & 20 & 33.3 \\
\hline \multicolumn{1}{c}{ Total } & 30 & 100 & 30 & 100 & 60 & 100 \\
\hline
\end{tabular}

Tabel 13. Sebaran Contoh berdasarkan Jenis Keluhan Sakit Selama 1 Bulan Terakhir

\begin{tabular}{lcccccc}
\hline \multirow{2}{*}{$\begin{array}{c}\text { Jenis } \\
\text { Keluhan Sakit }\end{array}$} & \multicolumn{2}{c}{ Sopir Kampus Dalam } & \multicolumn{2}{c}{ Sopir Leuwiliang } & \multicolumn{2}{c}{ Total } \\
\cline { 2 - 6 } & $\mathbf{n}$ & $\%$ & $\mathbf{n}$ & $\%$ & $\mathbf{n}$ & $\%$ \\
\hline Batuk & 5 & 16.7 & 1 & 3.3 & 6 & 10.0 \\
Demam/Masuk angin & 3 & 10.0 & 4 & 13.3 & 7 & 11.7 \\
Flu & 5 & 16.7 & 1 & 3.3 & 6 & 10.0 \\
Pusing/Sakit kepala & 7 & 23.3 & 12 & 40.0 & 19 & 31.7 \\
Sesak nafas & 1 & 3.3 & 2 & 6.7 & 3 & 5.0 \\
Sakit gigi & 1 & 3.3 & 0 & 0.0 & 1 & 1.7 \\
Sakit perut (Gastritis) & 0 & 0.0 & 2 & 6.7 & 2 & 3.3 \\
Diare & 0 & 0.0 & 1 & 3.3 & 1 & 1.7 \\
Sulit BAB & 1 & 3.3 & 0 & 0.0 & 1 & 1.7 \\
Gangguan tekanan darah & 0 & 0.0 & 1 & 3.3 & 1 & 1.7 \\
(Hipertensi) & & & & & & \\
\hline
\end{tabular}




\section{Status Gizi}

Secara keseluruhan lebih dari separuh contoh mempunyai status gizi baik atau normal. Contoh yang mengalami underweight pada sopir Kampus Dalam jumlahnya lebih banyak (23.3\%) daripada sopir Leuwiliang. Pada Trayek Leuwiliang, contoh yang mengalami pre obese jumlahnya lebih banyak (23.3\%) daripa da sopir Kampus Dalam. Adapun sebaran contoh berdasarkan status gizi disajikan pada Tabel 14

Kegemukan saat dewasa sekarang ini banyak terjadi. Tanggung jawab terhadap pekerjaan yang semakin tinggi menyebabkan seseorang tidak mempunyai waktu untuk berolahraga. Oleh karena itu, jika kurang hati-hati mengontrol makanan dan segan melakukan aktivitas fisik, lambat laun tubuh akan menderita kegemukan. Padahal, jika kegemukan dibiarkan berlarut, maka tubuh akan dihinggapi berbagai penyakit degeneratif, seperti jantung koroner, diabetes mellitus, dan tekanan darah tinggi (Purwati et al., 2002).

\section{Hubungan Antar Variabel}

Proporsi terbesar contoh yang termasuk kategori pengetahuan gizi dan kesehatan tingkat rendah adalah memiliki keluhan kesehatan (83.3\%), begitu juga proporsi terbesar contoh yang termasuk kategori pengetahuan gizi dan kesehatan tingkat tinggi adalah yang memiliki keluhan kesehatan (66.7\%). Uji korelasi Spearman menunjukkan bahwa tingkat pengetahuan gizi dan kesehatan berhubungan positif namun tidak signifikan dengan keluhan kesehatan $(r=0.067, p>0.05)$.

Proporsi terbesar contoh yang memiliki perilaku hidup sehat cukup adalah memiliki keluhan kesehatan (66.7\%), begitu juga proporsi terbesar contoh yang memiliki perilaku hidup sehat baik adalah yang memiliki keluhan kesehatan (67.7\%). Uji korelasi Spearman menunjukkan bahwa perilaku hidup sehat berhubungan positif namun tidak signifikan dengan keluhan kesehatan $(r=0.067, p>0.05)$.

Proporsi terbesar contoh yang memiliki karakteristik lingkungan fisik rumah kurang adalah memiliki keluhan kesehatan (66.7\%), begitu juga proporsi terbesar contoh yang memiliki perilaku hidup sehat baik adalah yang memiliki keluhan kesehatan (60.0\%). Uji korelasi Spearman menunjukkan bahwa perilaku hidup sehat berhubungan positif namun tidak signifikan dengan keluhan kesehatan $(r=0.067$, $p>0.05)$. Sebaran contoh berdasarkan pengeta- huan gizi dan kesehatan, perilaku hidup sehat, serta karakteristik lingkungan fisik rumah hubungannya dengan keluhan kesehatan contoh disajikan pada Tabel 15.

Berdasarkan Indeks Massa Tubuh (IMT) terlihat bahwa proporsi terbesar contoh yang memiliki status gizi normal adalah yang memiliki keluhan kesehatan (76.5\%). Uji korelasi Spearman menunjukkan bahwa antara keluhan kesehatan dengan status gizi berhubungan negatif namun tidak signifikan $(r=-0.014, p>$ 0.05). Hal ini berarti bahwa terdapat kecenderungan contoh yang memiliki keluhan kesehatan akan mengalami penurunan status gizi, yang ditandai dengan menurunnya berat badan sehingga lebih rendah berat badannya dibanding keadaan sebelum sakit. Dalam keadaan sakit, umumnya terjadi penurunan nafsu makan sehingga intik zat gizi yang diperlukan berkurang (Utomo, 1988 dalam Nurwulan, 2003).

\section{KESIMPULAN}

Berdasarkan hasil penelitian terhadap 30 contoh sopir Kampus Dalam dan 30 contoh sopir Leuwiliang diketahui bahwa lebih dari separuh contoh $(53.3 \%)$ tergolong pada masa dewasa awal. Tingkat pendidikan formal yang pernah ditempuh oleh contoh sebesar 36.7\% adalah SLTA/sederajat. Separuh contoh (50\%) termasuk dalam kategori keluarga kecil. Lebih dari separuh contoh $(58.3 \%)$ tergolong dalam kategori keluarga tidak miskin.

Sebanyak 20\% contoh memiliki tingkat pengetahuan gizi dan kesehatan yang rendah. Lebih dari separuh contoh (68.3\%) memiliki kebiasaan olahraga, dan sebagian besar contoh (86.7\%) memiliki kebiasaan merokok. Sebanyak $15 \%$ contoh memiliki kebiasaan mengkonsumsi alkohol. Lebih dari separuh contoh (51.7\%) mempunyai kebiasaan makan 3 kali sehari dan selalu sarapan pagi (68.3\%). Berdasarkan susunan hidangan makanan, mayoritas contoh (70\%), mengkonsumsi makanan pokok, lauk pauk, dan sayuran. Lebih dari separuh contoh (53.3\%) memiliki kebiasaan minum air putih $\geq 8$ gelas per hari. Berdasarkan kategori perilak̄u hidup sehat, separuh contoh termasuk dalam kategori baik.

Berdasarkan kategori lingkungan fisik rumah, lebih dari separuh contoh $(51.7 \%)$ berada pada kategori baik. Lebih dari separuh contoh $(66.7 \%)$ memiliki keluhan kesehatan selama 
Tabel 14. Sebaran Contoh berdasarkan Status Gizi

\begin{tabular}{lcccccc}
\hline \multirow{2}{*}{ Status Gizi } & \multicolumn{2}{c}{ Sopir Kampus Dalam } & \multicolumn{2}{c}{ Sopir Leuwiliang } & \multicolumn{2}{c}{ Total } \\
\cline { 2 - 7 } & $\mathbf{n}$ & $\%$ & $\mathbf{n}$ & $\%$ & $\mathbf{n}$ & $\%$ \\
\hline Underweight $(I M T<18.5)$ & 7 & 23.3 & 2 & 6.7 & 9 & 15.0 \\
Normal $(18,5<\mid M T<24.9)$ & 15 & 50.0 & 19 & 63.3 & 34 & 56.7 \\
Pre obese $(25<\mid M T<29.9)$ & 6 & 20.0 & 7 & 23.3 & 13 & 21.7 \\
Obese 1 $(30<\mid M T<34.9)$ & 2 & 6.7 & 2 & 6.7 & 4 & 6.7 \\
\hline Total & 30 & 100 & 30 & 100 & 60 & 100 \\
\hline
\end{tabular}

Tabel 15. Sebaran Contoh berdasarkan Hubungan Antar Variabel

\begin{tabular}{|c|c|c|c|c|c|c|}
\hline \multirow{3}{*}{ Variabel } & \multicolumn{4}{|c|}{ Keluhan Kesehatan } & \multirow{2}{*}{\multicolumn{2}{|c|}{ Total }} \\
\hline & \multicolumn{2}{|c|}{ Ada Keluhan } & \multicolumn{2}{|c|}{ Tidak Ada Keluhan } & & \\
\hline & $\mathrm{n}$ & $\%$ & $n$ & $\%$ & $\mathrm{n}$ & $\%$ \\
\hline \multicolumn{7}{|c|}{ Pengetahuan Gizi dan Kesehatan } \\
\hline Rendah & 10 & 83.3 & 2 & 16.7 & 12 & 100.0 \\
\hline Sedang & 10 & 55.6 & 8 & 44.4 & 18 & 100.0 \\
\hline Tinggi & 20 & 66.7 & 10 & 33.3 & 30 & 100.0 \\
\hline Total & 40 & 66.7 & 20 & 33.3 & 60 & 100.0 \\
\hline \multicolumn{7}{|l|}{ Perilaku Hidup Sehat } \\
\hline Kurang & 1 & 50.0 & 1 & 50.0 & 2 & 100.0 \\
\hline Cukup & 18 & 66.7 & 9 & 33.3 & 27 & 100.0 \\
\hline Baik & 21 & 67.7 & 10 & 32.3 & 31 & 100.0 \\
\hline Total & 40 & 66.7 & 20 & 33.3 & 60 & 100.0 \\
\hline \multicolumn{7}{|l|}{ Karakteristik Lingkungan Fisik } \\
\hline Kurang & 2 & 66.7 & 1 & 33.3 & 3 & 100.0 \\
\hline Cukup & 20 & 74.1 & 7 & 25.9 & 27 & 100.0 \\
\hline Baik & 18 & 60.0 & 12 & 40.0 & 30 & 100.0 \\
\hline Total & 40 & 66.7 & 20 & 33.3 & 60 & 100.0 \\
\hline
\end{tabular}

Tabel 16. Sebaran Contoh berdasarkan Keluhan Kesehatan dan Status Gizi

\begin{tabular}{|c|c|c|c|c|c|c|}
\hline \multirow{3}{*}{ Status Gizi } & \multicolumn{4}{|c|}{ Keluhan Kesehatan } & \multirow{2}{*}{\multicolumn{2}{|c|}{ Total }} \\
\hline & \multicolumn{2}{|c|}{ Ada Keluhan } & \multicolumn{2}{|c|}{ Tidak Ada Keluhan } & & \\
\hline & $n$ & $\%$ & $n$ & $\%$ & $\mathrm{n}$ & $\%$ \\
\hline Underweight & 4 & 44.4 & 5 & 55.6 & 9 & 100.0 \\
\hline Normal & 26 & 76.5 & 8 & 23.5 & 34 & 100.0 \\
\hline Pre Obese & 8 & 61.5 & 5 & 38.5 & 13 & 100.0 \\
\hline Obese 1 & 2 & 50 & 2 & 50 & 4 & 100.0 \\
\hline Total & 40 & 66.7 & 20 & 33.3 & 60 & 100.0 \\
\hline
\end{tabular}

satu bulan terakhir. Secara keseluruhan, lebih dari separuh contoh mempunyai status gizi baik atau normal, sebesar $21.7 \%$ pre obese, $15 \%$ underweight, dan $6.7 \%$ obese.

Tingkat pengetahuan gizi dan kesehatan serta perilaku hidup sehat berhubungan positif namun tidak signifikan dengan keluhan kesehatan. Adapun karakteristik lingkungan fisik rumah berhubungan negatif namun tidak signifikan terhadap keluhan kesehatan contoh. Keluhan kesehatan berhubungan negatif dengan status gizi namun tidak signifikan.
Contoh pada sopir Leuwiliang lebih banyak yang mengalami keluhan sakit selama satu bulan terakhir. Hal ini berhubungan dengan skor perilaku hidup sehat yang masih rendah, kebiasaan olahraga yang rendah, kebiasaan merokok yang tinggi, dan kebiasaan konsumsi alkohol yang lebih banyak daripada sopir Kampus Dalam.

\section{DAFTAR PUSTAKA}

As-Sayyid ABM. 2006. Pola Makan Rasulullah. Almahira, Jakarta. 
Azwar A. 1983. Pengantar Pendidikan Kesehatan. PT Sastra Hudaya, Jakarta Pusat.

[BPS] Badan Pusat Statistik. 2007. Data dan Informasi Kemiskinan 2005-2006. BPS Kabupaten, Jakarta

Emoto M. 2006. The True Power of Water. Azam Translator, penerjemah. MQ Publishing, Bandung

Faiz MH. 2008. Problem-problem Perkembangan Sosial pada Setiap Periode Perkembangan. [terhubung berkala]. http: //www.faizperjuangan.wordpress.com. [29 April 2008].

Hidayat A. 2008. Kontribusi Pendidikan Terhadap Pertumbuhan Ekonomi. [terhubung berkala]. http://www.educare.e-fkipun la.net. [30 Mei 2008].

Khomsan A. 2000. Teknik Pengukuran Pengetahuan Gizi. Jurusan Gizi Masyarakat dan Sumberdaya Keluarga Fakultas Pertanian, Institut Pertanian Bogor, Bogor.

Khomsan A. 2002. Pangan dan Gizi untuk Kesehatan. Jurusan Gizi Masyarakat dan Sumberdaya Keluarga, Fakultas Pertanian Institut Pertanian Bogor, Bogor.

Kusnoputranto H. 1995. Toksikologi Lingkungan. Fakultas Kesehatan Masyarakat dan Pusat Penelitian Sumberdaya Manusia dan Lingkungan, Universitas Indonesia.

Luize A. 2003. Kurang Minum Bisa Timbulkan Stroke..!. [terhubung berkala]. http:// www.gizi.net. [8 Mei 2008].

Martianto D. 2007. Indikator Gizi dalam Pembangunan [diktat kuliah]. Ekonomi Pangan dan Gizi. Program Studi Gizi Masyarakat dan Sumberdaya Keluarga Fakultas Pertanian, Insitut Pertanian Bogor, Bogor.

Marut UD. 2008. Studi tentang Aspek Sosial Ekonomi dan Budaya serta Kaitannya dengan Masalah Gizi Kurang di Kabupaten Manggarai, Nusa Tenggara Timur [skripsi]. Departemen Gizi Masyarakat dan Sumberdaya Keluarga, Fakultas Pertanian, Institut Pertanian Bogor, Bogor.

Notoatmodjo S. 2007. Promosi Kesehatan dan Ilmu Perilaku. PT Rineka Cipta, Jakarta.
Nurwulan I. 2003. Hubungan Karakteristik Lingkungan Fisik Rumah, Perilaku Hidup Sehat serta Akses Terhadap Pelayanan Kesehatan dengan Status Kesehatan Anak Usia 3-5 Tahun pada Keluarga Miskin di Kecamatan Bogor Selatan [skripsi]. Departemen Gizi Masyarakat dan Sumberdaya Keluarga Fakultas Pertanian, Institut Pertanian Bogor, Bogor.

Palestin B. 2006. Pengaruh Umur, Depresi dan Demensia Terhadap Disabilitas Fungsional Lansia (Adaptasi Model Sistem Neuman). [terhubung berkala]. http: //www.bondankomunitas.blogspot.com [30 Mei 2008].

Ramaiah S. 2007. All You Wanted To Know About Hipertensi. Buana IImu Populer, Jakarta

Purwati et al. 2002. Perencanaan Menu Untuk Penderita Kegemukan. Penebar Swadaya, Jakarta

Slamet Y. 1993. Analisis Kuantitatif Untuk Data Sosial. Dabara Publisher, Solo.

Soemarwoto O. 2004. Udara Segar Kian Mahal. [terhubung berkala]. http://www. pikiranrakyat.com. [23 November 2007].

Sumarwan U. 2004. Perilaku Konsumen. Ghalia Indonesia, Bogor.

Tandra H. 2006. Merokok dan Kesehatan. Di dalam: Makan Sehat Hidup Sehat. Penerbit Buku Kompas, Jakarta.

[UNDP] United Nation and Development Programme. 2007. 2007/2008 Human Development Index rankings. [terhubung berkala]. http:// www.hdr.undp.org. [14 Februari 2008].

[WHO] World Health Organization. 1988. Pendidikan Kesehatan. Ida Bagus Tjitarsa, penerjemah. Bandung, Penerbit ITB dan Penerbit Universitas Udayana. Terjemahan dari: Education for Health : A Manual on Health Education in Primary Health Care.

Wirakusumah E. 2001. Menu Sehat untuk Lanjut Usia. Puspa Swara, Jakarta. 